\title{
Educación Primaria con Covid-19, en el 2020
}

\author{
Andrés Elías Gómez Alfonzo \\ andreselias18@gmail.com \\ Universidad de Carabobo \\ Valencia - Venezuela
}

\section{RESUMEN}

Este ensayo nace debido a las diversas perspectivas que se obtuvieron por las quejas y comentarios que realizaron muchos padres, representantes y familiares de los estudiantes de primaria, quienes recientemente se habían iniciado en su etapa formativa. Aunado a las diversas perspectivas de esta problemática que los docentes también han publicado a través de artículos y comentarios en prensa. Todo esto sucede por la emergencia generada por la pandemia producida por el COVID-19, no solo en Venezuela sino a nivel mundial. Pero se encontraron con el impacto de cómo garantizar la formación educativa básica de los niños; por ello muchos gobiernos, entre ellos el venezolano, precisó el continuar el proceso educativo mediante el uso de sistemas telemáticos. Este análisis resalta parte de la diversidad de hechos que se unen a la problemática formativa, tales como diferencias e inequidades sociales que existen entre los distintos sectores de la población. Analizándose también, que la virtualidad de la educación, ha afectado en mayor medida, a los estudiantes de los estratos socioeconómicos más desfavorecidos.

Palabras Claves: covid-19; educación primaria; familiares; educador. 


\title{
Primary Education with Covid-19, in 2020
}

\begin{abstract}
This essay was born due to the diverse perspectives that were obtained by the complaints and comments made by many parents, representatives and relatives of elementary school students, who had recently started in their formative stage. In addition to the various perspectives on this problem that teachers have also published through articles and comments in the press. All this happens due to the emergency generated by the pandemic produced by COVID-19, not only in Venezuela but also worldwide. But they found the impact of how to guarantee the basic educational training of children; For this reason, many governments, including the Venezuelan, needed to continue the educational process through the use of telematic systems. This analysis highlights part of the diversity of facts that are linked to the formative problem, such as social differences and inequities that exist between the different sectors of the population. Analyzing also, that the virtuality of education, has affected to a greater extent, students from the most disadvantaged socioeconomic strata.
\end{abstract}

Key Words: covid-19; primary education; teacher.

Artículo recibido: 10. Junio. 2021 Aceptado para publicación: 16. Julio. 2021 Correspondencia: Andreselias18@gmail.com Conflictos de Interés: Ninguna que declarar 


\section{INTRODUCCIÓN}

Siendo el COVID-19 o coronavirus, un grupo de virus que causan enfermedades que van desde el resfriado común hasta enfermedades más graves como neumonía, síndrome respiratorio de Oriente Medio (MERS) y síndrome respiratorio agudo grave (SARS). Chacha (2020: 1) menciona en su estudio, que "los coronavirus ( $\mathrm{CoV}$ ) son una gran familia de virus que causan enfermedades que van desde el resfriado común hasta enfermedades más graves". Cabe destacar que la cepa de coronavirus (2019-nCoV) que ha causado el brote en China es nueva y no se conocía previamente. En cuanto a su comienzo, todavía no se ha confirmado el posible origen animal de la COVID-19.

García (2020) expresa que la pandemia del COVID-19 es uno de los desafíos más serios que ha enfrentado la humanidad en tiempos recientes. Todavía se desconoce lo que podrá ser su costo total en vidas humanas. Cabe resaltar que no se había planificado el cómo reaccionar ante una emergencia sanitaria que generó el COVID-19, todos los países del mundo se vieron obligados a suspender las actividades escolares presenciales, de manera internacional a través de los medios informativos se conoció que en todos los niveles educativos y, fue generado como estrategia para resguardar la salud, tanto de los estudiantes como de los docentes, padres y representantes. Pero se encontraron con el impacto de cómo garantizar la formación educativa básica de los niños; por ello muchos gobiernos, entre ellos el venezolano, precisó el continuar el proceso educativo mediante el uso de sistemas educativos telemáticos.

Plena Inclusión (2020) señala, que no se puede dejar a un lado que la educación es vital para los niños y que, "los cambios que está sufriendo la convivencia familiar durante esta crisis: situaciones de desempleo, de enfermedad, fallecimiento y duelo, que suponen una alteración de la dinámica habitual, influye en el proceso educativo". Siendo difícil de comprender o asimilar y esto lo convierte en disparadores de estrés que pueden acelerar las dificultades durante la convivencia.

Es por ello que la estrategia educativa, que se está padeciendo de manera reciente en muchas partes del mundo, resalta las desigualdades e inequidades sociales que existen entre los distintos sectores de la población. La educación, precisan 
Suárez, Rivera-Vargas y Rebour (2020), a través del uso de internet ha puesto de manifiesto las brechas educativas entre los estudiantes. El paso de la presencialidad a la virtualidad de la educación, ha afectado, en mayor medida, a los estudiantes de los estratos socioeconómicos más desfavorecidos, a los estudiantes de la educación pública, más todavía, a los que residen en zonas rurales, y aún más, a los estudiantes con padres con bajos niveles de instrucción. En general, se puede afirmar que en lugar de apoyar la adquisición de conocimientos se exacerba las desigualdades educativas del estudiantado.

Al respecto, Arce (2020: 13) señala una realidad latente, muchos pensaban que "la educación virtual parecía lejana a muchos de nosotros, tuvimos que perder el miedo y atrevernos a utilizar herramientas tecnológicas y pedagógicas de manera virtual para sacar adelante la clase". Tuvieron que colmarse de ánimo y valor, tanto los docentes como los padres y representantes de los estudiantes; es decir, integrarse de forma enérgica y esforzarse a fin de alcanzar las metas educativas requeridas para formar a los niños de educación primaria, quienes han sido los que han tenido mayores dificultades para integrarse al nuevo sistema educativo por cuanto no tienen suficientes conocimiento en el manejo de ordenadores y/o teléfonos inteligentes y las herramientas educativas que estos equipos integran.

Ahora bien, luego de la improvisación educativa a partir del inicio de la pandemia en el área educativa y específicamente en la educación básica, afirma VicenteFernández (2020) que los docente se vieron en la necesidad de buscar herramientas y medios tecnológicos, es decir, herramientas y estrategias; por lo cual, gran cantidad de docentes, padres y familiares se vieron prácticamente obligados a dejar de evadir los medios tecnológicos actuales y enfrentar el utilizar esas herramientas pedagógicas, como una de las vías para poder instruir a los estudiantes, aunque fuera de manera virtual y con la necesidad de intervención más comprometida por parte de sus padres, madres y/o representantes, o algún familiar que pudiera responder a las dudas, inquietudes y dificultades que tuviera el estudiante, todo esto fue parte de lo trajo consigo la pandemia.

Cabe destacar, la opinión emitida por Vivanco-Saraguro (2020: 2), cuando expresó que, como solución educativa luego de la pandemia, "los centros escolares y profesorado necesitarían de la colaboración con múltiples socios para 
enseñar al alumnado a mitigar los problemas de inclusión y equidad durante la pandemia"; lucha que todavía hoy en día se presenta. Este precitado autor menciona, que no se puede dejar a un lado que un número muy alto de docentes ha permitido resaltar la importancia del deber actuar como un auténtico equipo, en donde se exalten los valores y se propicien climas de esfuerzo y, se transmita una motivación que sostenga tanto a los centros educativos como a los hogares de estos educandos.

Según datos de la Organización de las Naciones Unidas para la Educación, la Ciencia y la Cultura (UNESCO), a mediados de mayo de 2020 más de 1.200 millones de estudiantes de todos los niveles de enseñanza, en todo el mundo, habían dejado de tener clases presenciales en la escuela. De ellos, más de 160 millones eran estudiantes de América Latina y el Caribe. Como se observa en el mapamundi emitido por la Unesco (2021), el índice de los países del mundo se vio directamente afectado por la pandemia de COVID-19, hecho que obligó a las escuelas y universidades a cerrar sus puertas, impactando a un número sin precedente de estudiantes en todo el mundo; todo esto afectó y modificó la vida en los hogares de los educandos, principalmente los que estudian educación primeria, por el desconocimiento de sobre qué bases sustentarse para estudiar y adecuar el desarrollo cognitivo.

Figura 1. Seguimiento mundial de los cierres causados por el COVID-19


Fuente: UNESCO (2021). 


\section{Perspectivas brindadas por el Covid-19}

Adentrándose ante la inquietud generada, cuáles son las perspectivas de educación primaria, ahora que se tiene pandemia por el COVID-19, por cuanto se quiere conocer y plasmar, ¿cómo afectó estos cambios producidos a los estudiantes, a los familiares y a todos los integrantes de cada hogar, por la pandemia? Lo anteriormente expresado, son interrogantes que se realizan muchos investigadores, algunos de ellos afirman que "Nos enfrentamos a una catástrofe generacional que podría desperdiciar un potencial humano incalculable, minar décadas de progreso y exacerbar las desigualdades arraigadas", mencionó el Secretario General de las Naciones Unidas, en Noviembre del año próximo pasado.

Cabe resaltar, que Zea (2020) señala la distancia o el no recibir clases presenciales han hecho reconocer y aceptar que el aprendizaje requiere tutorización, orientación, guía y vínculo y, en este sentido, tópicos que el docente aplica en cada estudiante, siendo fundamental para que éste internalice cada conceptualización o proceso que requiere dominar. Sin embargo, Hermi y García (2020) señalan que el confinamiento del alumnado en sus hogares se ha convertido en una situación compleja, que en algunos casos ha interferido de manera negativa en el proceso de enseñanza- aprendizaje de los niños, ya que los niños requieren tutoría en el proceso de aprendizaje.

Está experiencia de confinamiento nunca antes vivida por los padres y/o familiares de los estudiantes de la educación primaria debe ser una experiencia compartida, así lo señala (Muñoz y Lluch, 2020) quién también menciona que, mientras la clase media está haciendo una especie de curso acelerado de homeschooling, también conocido como educación en familia, es una opción educativa a la que cada vez optan más personas en todo el mundo; sucede que otros grupos sociales o bien no están en casa porque están trabajando o no disponen de los medios, recursos o capacidades para convertirse en maestros de escuela en un mes de carreras y adaptación por la pandemia (Muñoz y Lluch, 2020).

No se puede obviar que este virus COVID-19, afecta por igual la vida de todos los humanos y ciertamente no conoce de clases explicativas ni nada de eso, pero 
sus consecuencias en los tópicos educativos son diferentes, según sea la posición de clase y de dónde se venga. Hall y Ochoa-Martínez (2020), señalan que que no es lo mismo estar en un inmueble cómodo y que posee excelente conexión a internet, en donde se cuenta con muchas personas o familiares del educando que puedan atender las tareas y actividades escolares asignadas vía web; que ser estudiante de una familia que vive en un lugar pequeño, sin conexión a Internet y ambos padres trabajan y no pueden atender las obligaciones escolares del menor. Este escenario es una realidad que acontece en muchos hogares, que tienen esas características, en Venezuela.

También es importante resaltar, señala Pérez (2020) que la educación escolar, desde la edad temprana, tiene estrecha relación con el desarrollo de la personalidad, las capacidades y aptitudes de cada niño, además de la internalización de cada posibilidad que posea éste, de manera de alcanzar el desarrollo autónomo de su ser.

\section{Realidad Educativa, luego de la Pandemia}

Muñoz y Lluch (2020) resaltan la presencia inevitable, a partir de la pandemia, de la familia de cada educando y la corresponsabilidad no solo en diálogo y cooperación con los centros educativos sino para combatir el sentimiento de soledad que puedan poseer los niños, porque una vez superada la crisis sanitaria volverán a abrir los sistemas educativos tradicionales, siendo esto una influencia positiva para la estabilidad del estudiante, ante las diversas variantes que a cada niño le ha tocado enfrentar en su proceso educativo.

Una vez que los gobiernos impusieron el estar restringidas las salidas, las clases y las actividades escolares, entre otros muchos tópicos; se convirtieron los centros familiares en el agente educativo de primer orden y por ende, la fuente de aprendizaje para cada niño. Valencia (2020) expone que surgieron cosas como: el presenciar con el estudiante las indicaciones impartidas por el docente, verificar la actuación del niño frente a las asignaciones ejecutadas tales como: tareas escolares, las cuales son diferentes actividades como exposiciones, pinturas, recortes, entre otros; debido a que conllevan cosas como exposiciones, pinturas, recortes, investigaciones, resolución de ejercicios matemáticos, entre otras. 
Es de importancia resaltar, Maris (2020), hace mención en su artículo que se enfrentan momentos difíciles en emergencia educativa, es decir, no dejar de recibir enseñanza, como sea más efectivo para el niño; por ello, los padres y familiares en cada hogar, se han visto obligados, como nunca antes, a guiar el proceso educativo de sus pupilos. En muchos casos, se han tenido que armar de valentía para tomar en sus manos la educación de sus hijos total y formal de sus hijos. Bajo esta perspectiva, las diferencias económicas hacen más evidentes; por cuanto ya era difícil que padres con niveles de formación bajo o medio-bajo, apoyaran satisfactoriamente a sus hijos en el proceso educativo, pedirles ahora a analfabetos digitales y funcionales que guíen a sus hijos, es cuesta arriba por no señalar que casi imposible.

Desde el punto de vista familiar y/o del hogar, Egúsquiza (2020) expone que la familia tiene que agregar a sus tareas domésticas habituales, la atención educativa del niño y no pueden dejar a un lado, sus labores en pro del beneficio económico familiar; por supuesto, que las familias tienen la posibilidad de contribuir favorablemente a la mejora educativa en el instante que refuerzan y prosiguen la labor que desempeña el centro escolar. Pero también, en muchos casos, los familiares, padres y/o representantes presionan al niño para cumplir con rapidez lo asignado, sin la pedagogía suficiente para atender todo lo prescrito por el docente.

Desde el punto de vista pedagógico, señala Zea (2020) las clases virtuales generan tensiones entre el docente y los estudiantes; porque no se permite establecer medios pedagógicos para cada caso en particular, ajustado a las necesidades de cada niño. Teniendo en cuenta, que se está enfrentando un trabajo coordinado con padres, madres o cuidadores para el acompañamiento y la mediación de los procesos educativos.

Desde el punto de vista social, la pandemia generó o contribuyó significativamente al aumento del desempleo y por ende de pobreza (CEPAL, 2020), sumado a otras vicisitudes como elevación de los niveles de violencia doméstica, deterioro de la salud física y mental. Todo esto genera un deterioro emocional, agobio y estrés entre el personal docente y los familiares de los niños educandos. 
En Venezuela, señala UNICEF Venezuela (2020) que en tiempos de pandemia, existen hogares, donde hay ausencia de personas/familiares que puedan guiar el proceso educativo y tareas escolares de los niños, a razón de que muchos padres y representantes tienen que salir de casa para desempeñar actividades laborales que le permitan conseguir el sustento diario para la familia, quedando los niños totalmente desorientados, y sin acompañamiento y supervisión del proceso educativo.

\section{A manera de cierre}

Es por todos conocidos que el sistema educativo a nivel mundial, se plantea la meta central de posibilitar la formación integral de cada estudiante; como una forma que cada persona pueda tener una respuesta a cada reto personal y social. Además de aprender a convivir de manera armónica y agradable y, al mismo tiempo de poder desarrollar su proyecto de vida personal, realizado con verdadera libertad, dignidad de persona, además del bienestar y desempeño en la sociedad. Los centros escolares presenciales tienen la meta principal de brindar un aprendizaje significativo, auténtico y funcional para cada estudiante; como forma que ello le permita desarrollarse como una persona apta y capaz de poder ejecutar todas las competencias esenciales para tener una vida digna y grata.

Cada docente debe transmitir a través de las clases virtuales sentimientos positivos y de bienestar a sus educandos, y motivar a la colaboración de la familia en el proceso educativo del niño, de igual manera contribuir a mejorar los procesos formativos y de valores en los niños.

Por otro lado, hacen mención Corral y Corral (2020), que se debe hacer mención a la existencia de ciertos peligros o diferencias de estatus de vida, que están en ese proceso educativo, que tiene relación directa con ese familiar que se le modificó su horario y se cambió la distribución de su tiempo, además de la sobrecarga de tareas escolares, propiciando esto ansiedad y confusión, la desconfianza en las decisiones adoptadas o algunas actitudes del todo inapropiadas frente al menor, que no comprende completamente todo lo que está sucediendo.

Obviamente no puede permitir que las diversas circunstancias que se viven, en cuanto a los aspectos educativos, eliminen el derecho a la educación que tiene 
cada ser humano. Siempre hay que establecer estrategias y manera de permitir que accedan o cuente con los recursos que le sean necesarios para que pueda seguir aprendiendo. Cada docente, postula Arce (2020) debe considerar que en sus estudiantes se encuentren presentes las metas educativas vitales, tales como: inclusión, equidad y calidad de la educación.

Es vital contar con una verdadera colaboración por parte de las familias de cada uno de los estudiantes, teniendo diversidad de necesidades que atender por cuanto habrá algunos que tiempo, formación, materiales de apoyo, soportes técnicos, intercambios de prácticas y experiencias, sistemas de evaluación en consonancia, entre otros, poseen... pero hay otros que no. Al docente se debe mentalizar que ahora debe actuar de forma abierta y flexible, frente a tantas variaciones con que se puede contar, según sea cada estudiante; debe considerar la realidad de cada entorno y propiciar un adecuado nivel de colaboración con cada familia. Es un trabajo en equipo, donde todos trabajan por el bienestar del estudiante.

No se puede dejar a un lado, destaca OCDE (2020: 13) que "la etapa de recuperación del COVID-19, será esencial reflexionar sobre la función de los sistemas educativos", por cuanto esta crisis mundial de salud “...renovaron nuestra percepción de su valor para la sociedad". No se puede obviar que la pandemia de COVID-19, exacerbó las desigualdades sociales, la inequidad y la exclusión, hablando exclusivamente de la educación, en particular la formación en los primeros años educativos; siendo esto también una oportunidad para el fortalecimiento de las relaciones sociales, guiadas por sentimientos de solidaridad y colaboración en torno a la búsqueda del bien común, y también por la responsabilidad de la formación educativa.

Por su parte, Valencia (2020) señala que esta situación puede ser vista como favorecedora de reasignar muchos de los vínculos sociales y, generadora por ende, de reestructuración de identidades, incluso del valor de ser un verdadero vecino, un amigo, un estudiante; por cuanto se ha visto el forjar el bien común en el corto plazo, a través de grandes y pequeñas acciones colectivas en el día a día que, sin ignorar las diferencias preexistentes pueden constituir en herramientas vitales para alcanzar el bien común. 
Cabe destacar, la UNESCO (2020) muestra que la crisis provocada por la pandemia tendrá un impacto significativo en dos niveles:

- Disminución de la inversión en educación durante la crisis, así como el costo adicional que resulte de ella.

- Una esperada reducción de los recursos financieros disponibles en el futuro para el sector educativo.

Dada la proyección más reciente de la CEPAL (2020d) de una contracción de la actividad económica regional y de una caída promedio del 9,1\% del PIB en América Latina y el Caribe, salvaguardar el financiamiento para la educación es una prioridad fundamental para proteger a los sistemas educativos nacionales de la exacerbación de las desigualdades en el acceso a la educación y la crisis de aprendizaje.

\section{REFERENCIAS}

Arce, F. (2020). Estrategias Didácticas en Primaria para Enfrentar la Pandemia. Observatorio de Innovación Educativa. Tecnológico de Monterrey. Recuperado de: https://observatorio.tec.mx/edu-bits-blog/estrategiasdidacticas-educacion-primaria-pandemia. [Consultado: marzo 13, 2021].

Chacha M., K. (2020). El impacto en la educación primaria tras la emergencia sanitaria ocasionada por la pandemia del COVID-19. Uma Editorial. Universidad de Málaga. Vol. 3 Núm. 2 (2020). Artículos. Publicado: ene 24, 2021. Recuperado de: https://revistas.uma.es/index.php/NEIJ/article/view/11187. [Consultado: mayo 5, 2021].

Comisión Económica para América Latina y el Caribe (2020). La educación en tiempos de la pandemia de COVID-19. Recuperado de: https://www.cepal.org/es/publicaciones/45904-la-educacion-tiempos-lapandemia-covid-19. [Consultado: marzo 13, 2021].

Corral, Y. y Corral, I. (2020). Una mirada a la educación a distancia y uso de las TIC en tiempos de pandemia revista de tecnología de información y Comunicación en Educación. Volumen 14, No 1. Enero-junio 2020. ISSN: 1856-7576/143-150143. 
http://servicio.bc.uc.edu.ve/educacion

/eduweb/v14n1/art12.pdf. [Consultado: mayo 5, 2021].

Egúsquiza Contreras, R. (2020). Competencias digitales en Docentes de Educación Primaria que aplican la enseñanza virtual en el contexto de aislamiento social obligatorio por Covid 19, Lima, 2020. Recuperado de: https://repositorio.ucv.edu.pe/handle/20.500.12692/50515. [Consultado: Mayo 5, 2021].

García, S. (2020). COVID-19 y educación primaria y secundaria: repercusiones de la crisis e implicaciones de política pública para América Latina y el Caribe. PNUD América Latina y el Caribe \#COVID19. Serie De Documentos De Política Pública. Recuperado de: https://reliefweb.int/sites/reliefweb.int/files/resources/ publicacion-covid-19-y-educacion-primaria-y-secundaria-alc.pdf. [Consultado: Mayo 1, 2021].

Hall, J. y Ochoa-Martínez, P. (2020). Enseñanza virtual en educación física en primaria en México y la pandemia por COVID-19. Recuperado de: http://revistacaf.ucm.cl/article/view/624/675. [Consultado: Mayo 5, $2021]$.

Hermi, M. y García, M. B. (2020). El Covid-19 en España y sus primeras consecuencias. Espaço e Economia: Revista Brasileira de Geografía Económica, (17), 1-20. Recuperado de: https://doi.org/10.4000/espacoeconomia.10142. [Consultado: Mayo 5, 2021].

Maris, L. (2020). ¿Cómo usar la tecnología para fortalecer la educación a distancia? Recuperado de: https://www.caf.com/es/conocimiento/visiones/2020/06/como-usar-latecnologia-para-fortalecer-la-educacion-a-distancia/. [Consultado: Mayo $5,2021]$.

Muñoz, J. y Lluch, L. (2020). Consecuencias del Cierre de Escuelas por el Covid19 en las Desigualdades Educativas. Revista Internacional de Educación para la Justicia Social, 2020, 9(3e). ISSN: 2254-3139. Revistas.UAM.es/riejs.. 
https://scholar.google.co.ve/scholar?hl=es\&as_sdt=0\%2C5\&as

_vis $=1 \& \mathrm{q}=$ covid $+19+\mathrm{y}+\mathrm{la}+$ educacion+escolares $\& \mathrm{btnG}=. \quad$ [Consultado:

Marzo 13, 2021].

OECD (2020). El impacto del COVID-19 en la educación. Información del Panorama de la Educación (Education at a Glance). México. Recuperado de:

https://www.oecd.org/centrodemexico/medios/EAG2020_COVID\%20Bro chure\%20ES.pdf. [Consultado: Mayo 5, 2021].

Organización de las Naciones Unidas para la Educación, la Ciencia y la Cultura (2021). Perturbación y Respuesta al Corona Virus. ¿Cómo estás aprendiendo durante la pandemia de COVID-19? Recuperado de: https://es.unesco.org

/covid19/educationresponse. [Consultado: Marzo 15, 2021].

Pérez López, E. (2020). Educación a distancia en tiempos de COVID-19: Análisis desde la perspectiva de los estudiantes universitarios. Recuperado de: http://revistas.uned.es/index.php/ried/article/view/27855/22055.

[Consultado: Mayo 5, 2021].

Plena Inclusión. (2020). El derecho a la educación durante el COVID19. Recuperado de: https://www.plenainclusion.org/sites/default/files/el_derecho_a_la_ educacion_durante_el_covid19.pdf. [Consultado: Mayo 5, 2021].

Suárez, C.; Rivera-Vargas, P. y Rebour, M. (2020). Repensar la educación en tiempos de COVID-19. El Diario de la Educación. Recuperado de https://eldiariodelaeducacion.com/2020/07/29/repensar-la-educacion-entiempos-de-covid-19/. [Consultado: Mayo 5, 2021].

UNICEF Venezuela (2020). Venezuela: Alternativas para la continuidad educativa ante el cierre preventivo de escuelas por el COVID-19 (26 de marzo 2020). Recuperado de: https://reliefweb.int/report/venezuelabolivarian-republic/venezuela-alternativas-para-la-continuidadeducativa-ante-el. [Consultado: Mayo 5, 2021].

Valencia, H. (2020). La Educación Primaria en Tiempo de la Pandemia del Covid-19. El Caso de Chile y Perú Durante el 2020. Universidad San 
Ignacio

de

Loyola.

Recuperado

de:

http://repositorio.usil.edu.pe/handle/USIL/10383. [Consultado: Marzo 13, 2021].

Vicente-Fernández, P. (2020). Padres ante el Desafío Educativo en situación de confinamiento: análisis comparativo entre Educación Infantil y Educación Primaria. Recuperado de: http://revistaestilosdeaprendizaje.com/ article/view/2155. [Consultado: Mayo 5, 2021].

Vivanco-Saraguro, A. (2020). Teleducación en tiempos de COVID-19: brechas de desigualdad. Universidad Andina Simón Bolívar. Revista Cienciamérica. Número Especial 2020. Corona Virus, Covid 19. QuitoEcuador. http://cienciamerica.uti.edu.ec/openjournal/index.php/uti/article/view/30 7. [Consultado: Marzo 13, 2021].

Zea, S. (2020). En Venezuela, los maestros se adaptan a un mundo COVID-19. Unicef América Latina y el Caribe. Unicef Venezuela. . Recuperado de: https://www.unicef.org/lac/historias/en-venezuela-los-maestros-seadaptan-a-un-mundo-covid-19. [Consultado: Marzo 13, 2021]. 